\title{
Synergistic antitumor effects of CDK inhibitor SNS-032 and an oncolytic adenovirus co-expressing TRAIL and Smac in pancreatic cancer
}

\author{
YUN GE $^{1 *}$, WEN LEI ${ }^{2 *}$, YINGYU MA $^{3}$, YIGANG WANG ${ }^{1}$, BUYUN WEI $^{1}$, XIAOYI CHEN $^{3}$, \\ GUOQING RU ${ }^{4}$, XIANGLEI $\mathrm{HE}^{4}$, XIAOZHOU MOU ${ }^{3}$ and SHIBING WANG ${ }^{3}$
}

\begin{abstract}
${ }^{1}$ Xinyuan Institute of Medicine and Biotechnology, College of Life Sciences, Zhejiang Sci-Tech University, Hangzhou, Zhejiang 310018; ${ }^{2}$ Department of Hematology, The First Affiliated Hospital, College of Medicine, Zhejiang University, Hangzhou, Zhejiang 310003; ${ }^{3}$ Clinical Research Institute; ${ }^{4}$ Department of Pathology, Zhejiang Provincial People's Hospital, Hangzhou, Zhejiang 310014, P.R. China
\end{abstract}

Received November 4, 2015; Accepted February 7, 2017

DOI: $10.3892 / \mathrm{mmr} .2017 .6472$

\begin{abstract}
Gene therapy using oncolytic adenoviruses is a novel approach for human cancer therapeutics. The current study aimed to investigate whether the combined use of an adenovirus expressing tumor necrosis factor-related apoptosis-inducing ligand (TRAIL) and second mitochondria-derived activator of caspase (Smac) upon caspase activation (ZD55-TRAIL-IETD-Smac) and cyclin-dependent kinase (CDK) inhibitor SNS-032 will synergistically reinforce their anti-pancreatic cancer activities. The experiments in vitro demonstrated that SNS-032 enhances ZD55-TRAIL-IETD-Smac-induced apoptosis and causes marked pancreatic cancer cell death. Western blot assays suggested that the SNS-032 intensified ZD55-TRAIL-IETD-Smac-induced apoptosis of pancreatic cancer cells by affecting anti-apoptotic signaling elements, including CDK-2, CDK-9, Mcl-1 and XIAP. Additionally, animal experiments further confirmed that the combination of SNS-032 and ZD55-TRAIL-IETD-Smac significantly inhibited the growth of BxPC-3 pancreatic tumor xenografts. In conclusion, the present study demonstrated that SNS-032 sensitizes human pancreatic cancer cells to ZD55-TRAIL-IETD-Smac-induced cell death in vitro and in vivo. These findings indicate that combined treatment with
\end{abstract}

Correspondence to: Mr. Shibing Wang or Dr Xiaozhou Mou, Clinical Research Institute, Zhejiang Provincial People's Hospital, 158 Shangtang Road, Hangzhou, Zhejiang 310014, P.R. China E-mail: shibwang@163.com

E-mail: mouxiaozhou@gmail.com

*Contributed equally

Key words: oncolytic adenovirus, tumor necrosis factor-related apoptosis-inducing ligand, second mitochondria-derived activator of caspase, SNS-032, pancreatic cancer
SNS-032 and ZD55-TRAIL-IETD-Smac could represent a rational approach for anti-pancreatic cancer therapy.

\section{Introduction}

Pancreatic cancer is a fatal disease and remains consistently lethal with a 5 -year survival rate of $<5 \%$ (1). The disease generally causes few or no symptoms during early stages, thus the majority of patients are diagnosed at an advanced or terminal stage and few are suitable for curative surgical resection. Gemcitabine-based chemotherapy is the only option for treatment of advanced disease. Development of resistance to gemcitabine is a major concern. FLFIRINOX is an emerging treatment that offers a better survival outcome compared with gemcitabine. However, this chemotherapy regimen induces increased toxicity and exhibits only modest results $(2,3)$. Thus, the development of novel methods for treating pancreatic cancer is urgently required.

Replication-selective oncolytic viruses (OVs) have emerged as promising therapeutic tools for cancer treatment with attractive advantages, including tumor-selective amplification and replication, thus inducing cancer cells lysis with minimal affect on normal tissues (4-9). Recently, $>12$ different oncolytic viruses are undergoing phase I-III clinical trials targeting different types of cancer (10). Oncolytic adenovirus is the first and most intensively investigated OV to date and H101 (a mutant with $E 1 B 55 K$ gene deleted) is now authorized in China for treatment of head and neck cancer (Oncorine; Shanghai Sunway Biotech Co., Ltd., Shanghai, China) Our previous study developed a cancer-targeting dual-gene virotherapy (CTGVT-DG) strategy and generated a novel E1B55K gene deleted oncolytic adenovirus ZD55-TRAIL-IETD-Smac (ZD55-TIS) harboring tumor necrosis factor-related apoptosis-inducing ligand (TRAIL) and the second mitochondria-derived activator of caspase (Smac) genes joined by the four-amino acid isoleucine-aspartate-threonine-glutamate (IETD) linker (11). ZD55-TIS co-expressed TRAIL and Smac genes simultaneously and produced broad antitumor activity in vitro. Following intratumoral injection, the ZD55-TIS 
completely eradicated hepatocellar carcinoma cell xenograft tumors. However, the antitumor effects of ZD55-TIS against pancreatic cancer have not been evaluated.

The cyclin-dependent kinases (CDKs) are a family of serine/threonine kinases that control cell cycle events, and certain members are associated with transcriptional regulation. The tumor-specific deregulation makes the CDKs a major target for therapy $(12,13)$. SNS-032 is a effective and selective inhibitor of CDK2, -7, and -9 (13). It has been reported that SNS-032 has antitumor activity in various tumors (14-17). Based on the report which suggesting that aberrant activation of CDKs and dysregulation of cell cycle progression is a feature of pancreatic cancer (18), the current study investigated whether SNS-032 is able to enhance the anticancer activity of ZD55-TRAIL-IETD-Smac against pancreatic carcinoma.

The present study examined whether the CDK inhibitor SNS-032 may enhance the antitumor activities of ZD55-TIS against pancreatic cancer. To the best of our knowledge, the present study is the first to demonstrate that ZD55-TRAIL-IETD-Smac co-operatively act on pancreatic cancer in vitro and in vivo for the first time. The present study indicated that combination therapy with ZD55-TRAIL-IETD-Smac and SNS-032 may be a practical novel strategy against pancreatic cancer in the future.

\section{Materials and methods}

Cell lines and viruses. Human pancreatic cancer cell lines PANC-1 and BxPC-3 and human embryonic kidney cell line HEK293 were obtained from the Cell Bank of Type Culture Collection of Chinese Academy of Sciences (Shanghai, China) and cultured in Dulbecco's modified Eagle's medium (Gibco; Thermo Fisher Scientific, Inc., Waltham, MA, USA) supplemented with $10 \%$ heat inactivated fetal bovine serum (Gibco; Thermo Fisher Scientific, Inc.). Cells were incubated in a 5\% $\mathrm{CO}_{2}$ humidified incubator at $37^{\circ} \mathrm{C}$.

Construction and production of recombinant oncolytic adenovirus ZD55-TIS were described previously (11). The amplification of recombinant adenovirus was performed by infecting HEK293 cells.

Cytotoxicity assay and quantitative analysis of synergy in vitro. SNS-032 (Selleck Chemicals, Houston, TX, USA) was prepared at $1 \mathrm{mg} / \mathrm{ml}$ in dimethyl sulfoxide, stored at $-20^{\circ} \mathrm{C}$, and then diluted as needed in cell culture medium. Cell viability was estimated by 3-(4,5-dimethylthiazol-2-yl)-2,5-diphenyltetrazolium bromide (MTT) assay. Briefly, PANC-1 and BxPC-3 cells were plated in 96-well plates $\left(1 \times 10^{4}\right.$ density) in $100 \mu$ l culture medium. Cells were treated with different treatments (ZD55-TIS and SNS-032) at the indicated concentrations. After 48 or $72 \mathrm{~h}$, MTT (Sigma-Aldrich; Merck KGaA, Darmstadt, Germany) solution $(10 \mu \mathrm{l}, 5 \mathrm{~g} / \mathrm{l})$ was added to the cells which were then cultured for a further $4 \mathrm{~h}$. Absorbance $(570 \mathrm{~nm})$ was measured using a DNA microplate reader (GENios model; Tecan, Maennedorf, Switzerland).

Hoechst 33342 staining assay. Hoechst 33342 staining was used to detect morphological features of cell apoptosis. PANC-1 cells were treated with SNS-032 or ZD55-TRAIL-IETD-Smac, or the combination of SNS-032 and ZD55-TRAIL-IETD-Smac. After treatment for $72 \mathrm{~h}, 1 \mathrm{mg} / \mathrm{ml}(5 \mu \mathrm{l})$ Hochest 33342 (Sigma-Aldrich, Merck KGaA) was added in the cells for $30 \mathrm{~min}$ and morphology was observed under an inverted fluorescence microscope. Untreated cells served as a control.

Flow cytometry analysis. PANC-1 cells were treated with ZD55-TRAIL-IETD-Smac [8 multiplicity of infection (MOI)], SNS-032 (160 ng/ml), or ZD55-TRAIL-IETD-Smac (8 MOI) plus SNS-032 (160 ng/ml). After $48 \mathrm{~h}$, apoptotic cells were detected by using Annexin V-fluorescein isothiocyanate (FITC) and propidium iodide (PI) double staining or PI staining alone following the manufacturer's instructiona. Cell apoptosis and cell cycle were examined using the FACStar cytofluorometer (BD Biosciences, Franklin Lakes, NJ, USA).

Western blot analysis. PANC-1 cells were collected and washed twice with $\mathrm{PBS}$, then lysed in radioimmunoprecipitation assay buffer $\left(4^{\circ} \mathrm{C}, 30 \mathrm{~min}\right)$. Protein concentrations were determined by bicinchoninic acid assay (Thermo Fisher Scientific, Inc.). Protein samples $(10 \mu \mathrm{g})$ were separated by $12 \%$ SDS polyacrylamide-gel and transferred to polyvinylidene fluoride membranes. Membranes were blocked with 5\% bovine serum albumin (cat. no. P0007; Beyotime Institute of Biotechnology, Haimen, China), in a $10 \mathrm{mmol} / 1$ Tris- $\mathrm{HCl} \mathrm{pH} 8.0,150 \mathrm{mmol} / 1 \mathrm{NaCl}$ and $0.05 \%$ Tween-20 buffer overnight at $4^{\circ} \mathrm{C}$, and then incubated with the corresponding primary antibodies at 1:1,000 dilution overnight at $4^{\circ} \mathrm{C}$. Following incubation with horseradish peroxidase-conjugated secondary antibodies for $2 \mathrm{~h}$ at room temperature, signals were detected by enhanced chemiluminescence (ECL) with BeyoECL reagents (cat. no. P0018; Beyotime Institute of Biotechnology). Antibodies targeting Adenovirus-5 E1A (cat. no. sc-374663), caspase-3 (cat. no. sc-271759), poly (ADP-ribose) polymerase (PARP; cat. no. sc-56197), caspase-8 (cat. no. sc-166596) and GAPDH (cat. no. sc-47724) were purchased from Santa Cruz Biotechnology, Inc. (Dallas, TX, USA). Antibodies targeting CDK-2 (cat. no. 2546S), CDK-7 (cat. no. 2916), CDK-9 (cat. no. 2316S), BCL2 apoptosis regulator (Bcl-2; cat. no. 4223S), BCL2 family apoptosis regulator (Mcl-1; cat. no. 4572), X-linked inhibitor of apoptosis (XIAP; cat. no. 2042), TRAIL (cat. no. 3219S) and Smac (cat. no. 2954S) were obtained from Cell Signaling Technology, Inc. (Danvers, MA, USA). The secondary antibodies (cat. nos. 70-GAR007 for anti-rabbit and 70-GAM007 for anti-mouse) were purchased from MultiSciences (Hangzhou, China).

Animal experiments. Animal experiments were performed according to the Guide for the Care and Use of Laboratory Animals (National Institutes of Health, Bethesda, MD, USA) and in accordance with institutional standards. Male BALB/C nude mice (32 total) aged 5 weeks were purchased from the Shanghai Experimental Animal Center of Chinese Academy of Science (Shanghai, China). The mice were adapted to animal housing at $25^{\circ} \mathrm{C}$. BxPC-3 cells $\left(7 \times 10^{6}\right.$ cells in $100 \mu \mathrm{l}$ serum-free DMEM/mouse) were subcutaneously injected into the right flank of male nude mice. Mice were checked three times per week for tumor development. Once 
subcutaneous tumors reached $\sim 100-150 \mathrm{~mm}^{3}$, the nude mice were randomly divided into four groups ( $n=7$ per group). Subsequently, mice were injected with ZD55-TIS, SNS-032, a combination of the virus and the drug, or PBS. ZD55-TIS ( $1 \times 10^{9}$ plaque-forming units per mouse) was delivered via an intratumor injection, while SNS-032 was intraperitoneally injected into the mice at a dose of $30 \mathrm{mg} / \mathrm{kg}$ body weight or $100 \mu \mathrm{l}$ PBS as control by intratumor injection for three times of continuous injection once every other day. Tumor volume was measured with a vernier caliper every 4 days as calculated as follows: Tumor volume $\left(\mathrm{mm}^{3}\right)=\left(\mathrm{AxB}^{2}\right) / 2 ; \mathrm{A}$ and $\mathrm{B}$ are the tumor length and width (in $\mathrm{mm}$ ), respectively. The tumor volumes were used the produce tumor volume growth curves. The mice were sacrificed at 60 days post-tumor cell injection.

Hematoxylin and eosin $(H \& E)$ staining, immunohistochemistry and terminal deoxynucleotidyl transferase-mediated dUTP-biotin nick end labeling (TUNEL) assay. Tumor tissues were fixed in $4 \%$ paraformaldehyde and embedded in paraffin wax. The sections from tumors were stained with H\&E for histological analysis. For immunohistochemistry, formalin-fixed, paraffin-embedded tissue sections were cut at a thickness of $4 \mu \mathrm{m}$. For heat-induced epitope retrieval, tissue sections were deparaffinized and rehydrated in $0.01 \mathrm{M}$ $\mathrm{pH} 6.0$ citrate buffer 3 times at $90^{\circ} \mathrm{C}$ for 5 min using a microwave oven. Immunohistochemical staining was performed using the streptavidin-biotin immunoperoxidase technique. Endogenous peroxidase activity was blocked by incubation with $0.3 \% \mathrm{H}_{2} \mathrm{O}_{2}$ in methanol for $15 \mathrm{~min}$, and nonspecific immunoglobulin binding was blocked by incubation with $5 \%$ normal rabbit serum (cat. no. ZLI-9025; ZSGB-BIO Beijing, China) for $10 \mathrm{~min}$. Sections were incubated at $4^{\circ} \mathrm{C}$ overnight with primary antibodies at 1:50 dilution. Antibodies targeting CDK-2 (cat. no. 2546S), CDK-7 (cat. no. 2916), and CDK-9 (cat. no. 2316S) were from Cell Signaling Technology, Inc., and antibodies targeting E1A (cat. no. sc-374663), TRAIL (cat. no. sc-4547), and Smac (cat. no. sc-136302) were from Santa Cruz Biotechnology, Inc. The sections were rinsed and incubated for $30 \mathrm{~min}$ at room temperature with biotinylated secondary antibody at 1:100 dilution (cat. no. PV8000; ZSGB-BIO). Following washing, the sections were incubated for another $30 \mathrm{~min}$ with horseradish peroxidase-conjugated streptavidin (cat. no. ZLI-9017; ZSGB-BIO), and finally treated with 3,3'-diaminobenzidine tetrahydrochloride as a substrate for $10 \mathrm{~min}$. For the TUNEL assay, an in situ cell apoptosis detection kit (Roche Diagnostics, Indianapolis, IN, USA) was used, according to the manufacturer's instructions. PBS-treated tissue sections were used as a negative control. Hematoxylin was used as counterstain. Bright field microscopy was used to examine sections.

Statistical analysis. The experimental results are expressed as the mean \pm standard deviation. Statistical significance was analyzed by GraphPad 6.0 software (GraphPad Software, Inc., La Jolla, CA, USA). For comparison of two groups, two-tailed unpaired $t$-test was used. For comparison of more than two groups, one-way analysis of variance followed by Tukey's post hoc test was used. $\mathrm{P}<0.05$ was considered to indicate a statistically significant difference.

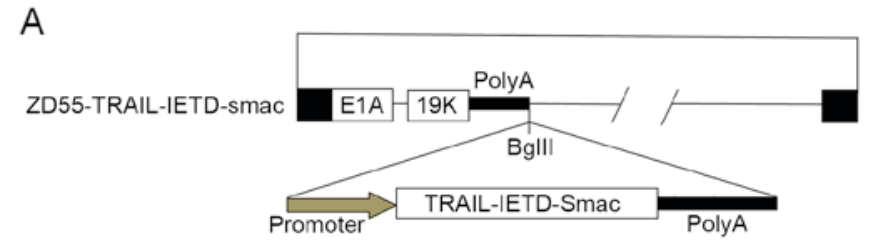

B

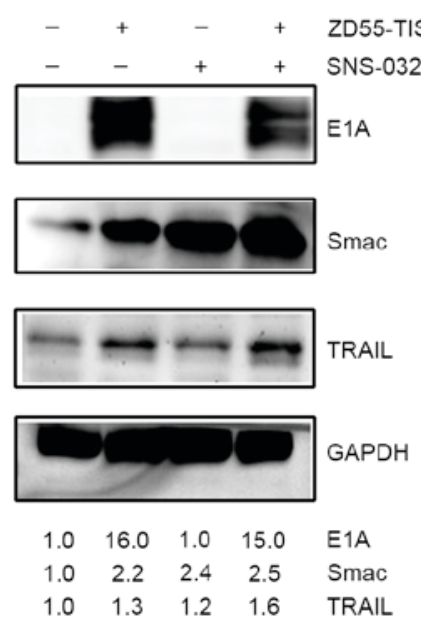

C

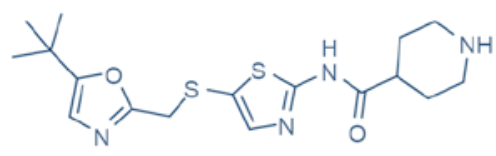

SNS-032 [MW: 380.53]

$\mathrm{N}$-(5-((5-tert-butyloxazol-2-yl)methylthio)thiazol-2-yl) piperidine-4-carboxamide

Figure 1. Characterization of oncolytic adenovirus ZD55-TIS and structure of SNS-032. (A) Schematic diagram of the oncolytic adenovirus ZD55-TIS. (B) Identification of recombinant adenovirus by western blot analysis ZD55-TIS (8 MOI), SNS-032 (160 ng/ml), or ZD55-TIS plus SNS-032 was used to treat PANC-1 cells for $48 \mathrm{~h}$. Cell proteins were collected to determine the expression of E1A, Smac and TRAIL. Untreated cells were used as a control group. Differences in protein expression level is semi-quantitatively determined by densitometry and expressed as a value relative to untreated cells. GAPDH was used as a protein loading control. (C) Schematic diagram of SNS-032 $\left(\mathrm{C}_{17} \mathrm{H}_{24} \mathrm{~N}_{4} \mathrm{O}_{2} \mathrm{~S}_{2}\right)$. ZD55-TIS, ZD55-TRAIL-IETD-Smac; TRAIL, tumor necrosis factor-related apoptosis-inducing ligand; IETD, isoleucine-aspartate-threonine-glutamate; Smac, second mitochondria-derived activator of caspase; MW, molecular weight.

\section{Results}

SNS-032 enhances ZD55-TRAIL-IETD-Smac-mediated growth inhibition in pancreatic cancer cells. The oncolytic adenovirus vector, ZD55, was constructed by deleting the E1B 55-kDa gene of adenovirus 5, which can selectively replicate in various tumor cells. Based on the Cancer Targeting Gene-Viro-Therapy, ZD55 was used to package the dual therapeutic gene TRAIL and Smac linked via a caspase- 8 cleavage site (IETD) to obtained the novel recombinant oncolytic adenovirus, ZD55-TRAIL-IETD-Smac (Fig. 1A). To validate the characterization of ZD55-TRAIL-IETD-Smac, western blot analysis was performed to detected the protein expression of the adenovirus E1A, and therapeutic genes TRAIL and Smac. The strong expression of E1A, TRAIL and Smac in PANC-1 cells infected with ZD55-TRAIL-IETD-Smac indicated that 
A

BxPC-3 $48 \mathrm{H}$
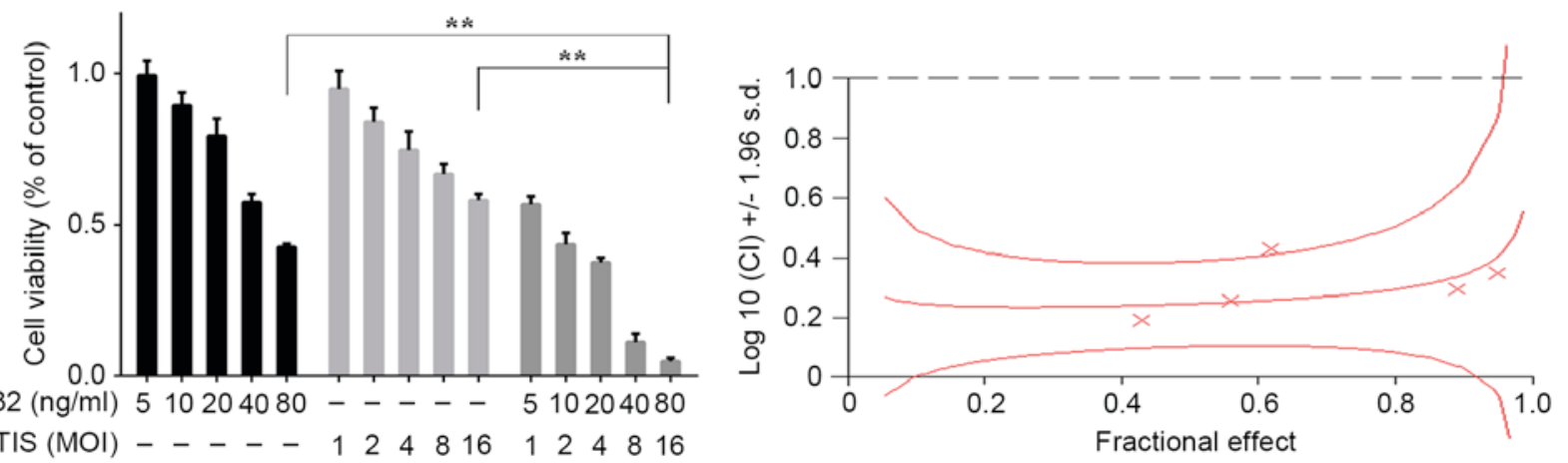

B
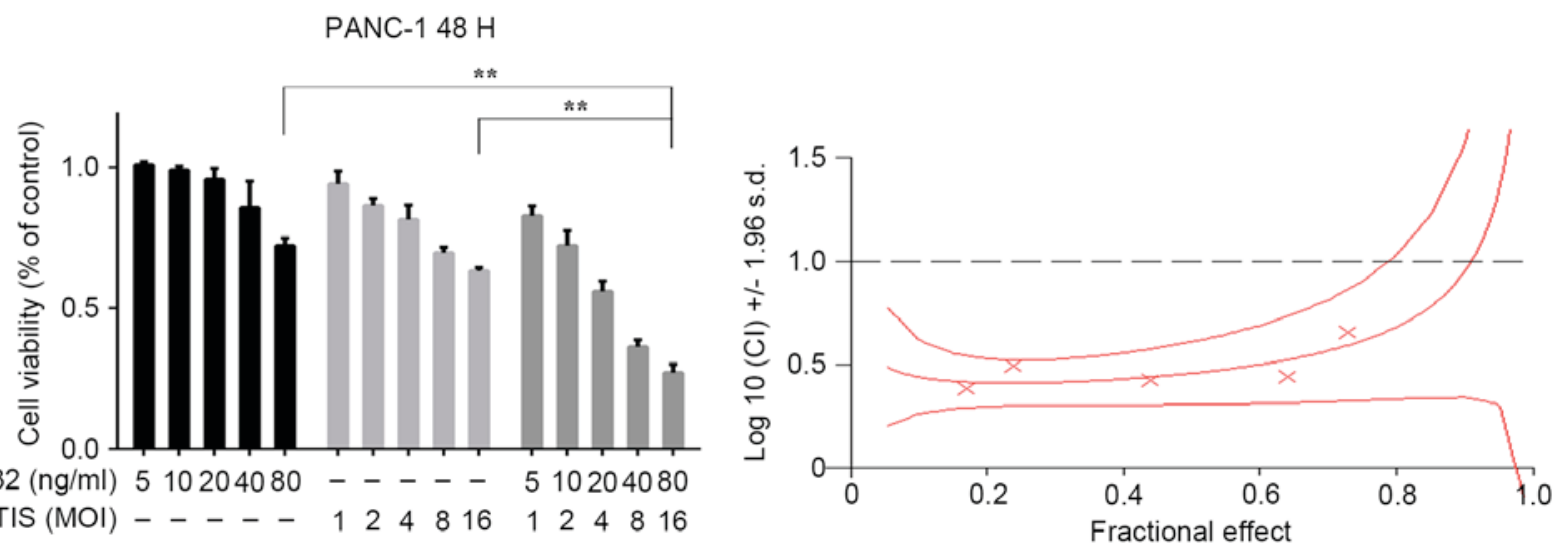

Figure 2. Combination of ZD55-TIS and SNS-032 enhances suppression of tumor cell proliferation. Pancreatic cancer cells (A) PANC-1 and (B) BxPC-3 were treated with ZD55-TIS (1, 2, 4, 8 and $16 \mathrm{MOI})$, SNS-032 (5, 10, 20, 40 and $80 \mathrm{ng} / \mathrm{ml})$, or ZD55-TIS plus SNS-032 for $48 \mathrm{~h}$. The image represents three independent experiments. Cell viability was evaluated by MTT assay and the synergistic effect of ZD55-TIS combined with SNS-032 on PANC-1 and BxPC-3 was quantified by $\mathrm{CI}$ analysis and expressed as $\log (\mathrm{CI})$ vs. fractional effect. Where calculable, 95\% confidence intervals are shown. ${ }^{* *} \mathrm{P}<0.05$. ZD55-TIS ZD55-TRAIL-IETD-Smac; TRAIL, tumor necrosis factor-related apoptosis-inducing ligand; IETD, isoleucine-aspartate-threonine-glutamate; Smac, second mitochondria-derived activator of caspase; CI, combination index.

ZD55-TRAIL-IETD-Smac can selectively replicate at high levels in pancreatic cancer cells (Fig. 1B).

To assess whether the CDK inhibitor SNS-032 (Fig. 1C) enhances ZD55-TRAIL-IETD-Smac-induced cell death in pancreatic cancer cells, MTT assay was performed. PANC-1 and BxPC-3 pancreatic cancer cell lines were infected with ZD55-TRAIL-IETD-Smac and/or treated with SNS-032. The results suggest that the combination of ZD55-TRAIL-IETD-Smac and SNS-032 has an enhanced cytotoxic effect on pancreatic cancer cells compared with either ZD55-TRAIL-IETD-Smac or SNS-032 alone (Fig. 2A and B).

SNS-032 enhances ZD55-TRAIL-IETD-Smac-induced apoptosis and cell cycle arrest in pancreatic cancer cells. Subsequently, Hoechst 33342 staining was performed to observe the morphological alterations of PANC-1 cells treated with ZD55-TRAIL-IETD-Smac and/or SNS-032. The results in Fig. 3A demonstrated that compared with ZD55-TRAIL-IETD-Smac treatment alone, co-treatment with SNS-032 led to marked apoptosis characterized by chromatin condensation, nuclear fragmentation and apoptotic body formation.

Western blot analysis demonstrated that ZD55-TRAILIETD-Smac activated the caspase-dependent pathway, including activation of caspase- 9 and caspase- 3 , and cleavage of PARP, and this effect was further enhanced by co-treatment with SNS-032 and ZD55-TRAIL-IETD-Smac compared with either treatment alone (Fig. 3B).

To quantify the effects of SNS-032 on ZD55-TRAILIETD-Smac-induced apoptosis, Annexin V-FITC/PI double staining was used to analyze cell apoptosis (Fig. 3C). The results demonstrated that the apoptotic rate of PANC-1 cells co-treated with ZD55-TRAIL-IETD-Smac and SNS-032 was $40.93 \%$, which was nearly 4 -fold more than that of ZD55-TRAIL-IETD-Smac treatment alone (9.67\%).

Furthermore, to determine whether the anti-proliferative effects of ZD55-TRAIL-IETD-Smac and SNS-032 may also cause cell cycle arrest, cell cycle analyses were performed on PANC-1 cells treated for $48 \mathrm{~h}$. As demonstrated in Fig. 3D, when used individually, treatment with ZD55-TRAIL-IETD-Smac or SNS-032, 12.9 or $16.7 \%$ cells, respectively, were in the G2 cell cycle phase. However, treatment with a combination of ZD55-TRAIL-IETD-Smac and SNS-032 arrested a greater number of cells in the $\mathrm{G} 2$ phase (38.9\%).

SNS-032 synergized the anti-pancreatic cancer effect of ZD55-TRAIL-IETD-Smac by changing the expression of cell apoptosis signaling elements. In order to further investigate the potential mechanism of the synergistic effect of SNS-032 combined with ZD55-TRAIL-IETD-Smac, CDK-2, 
A

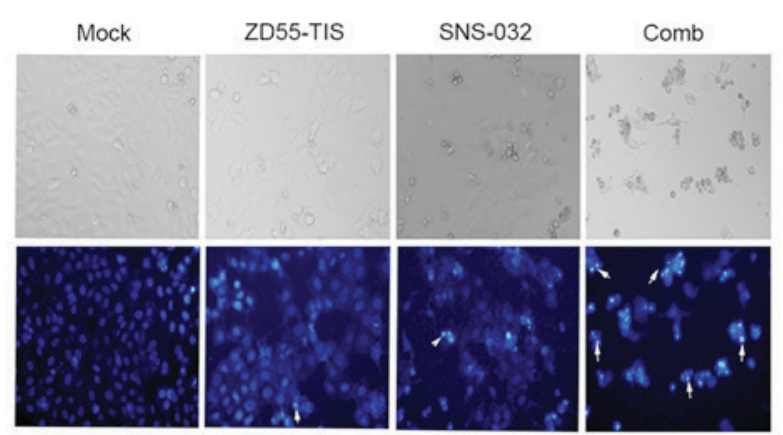

C

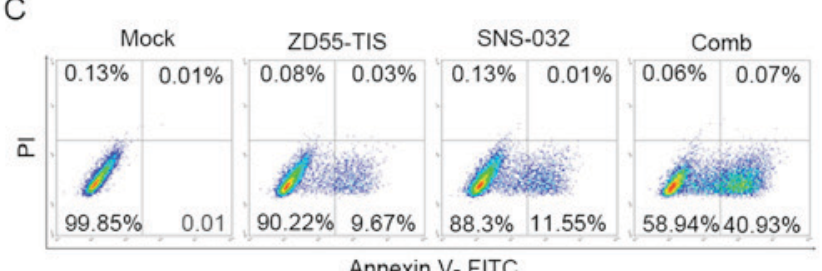

B
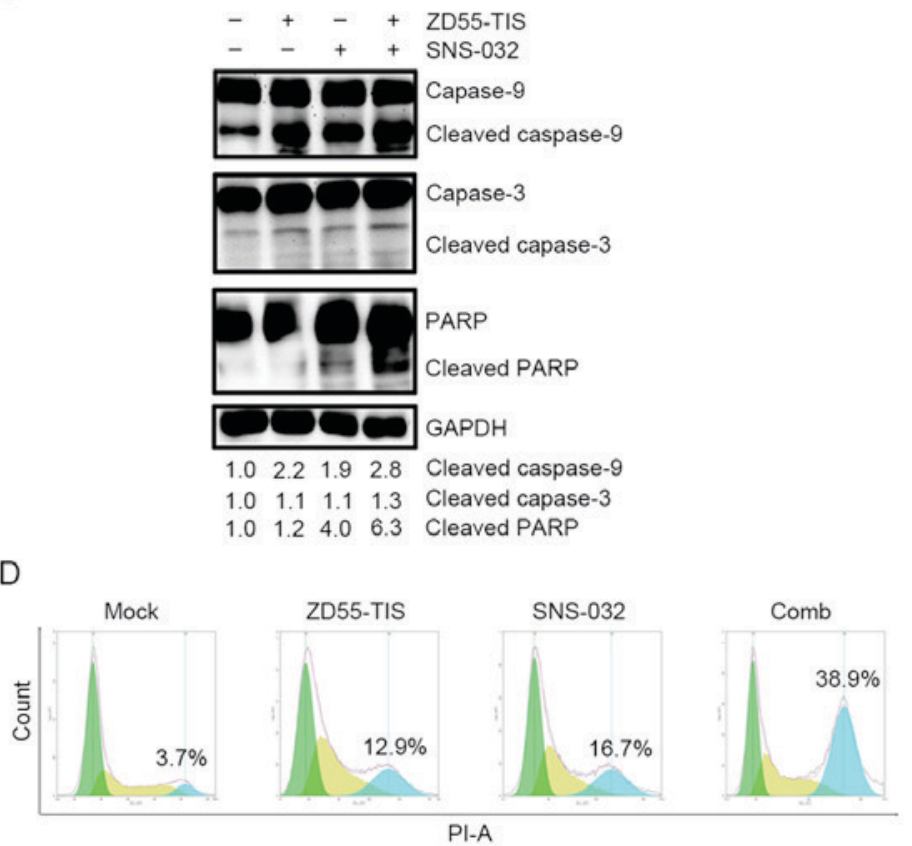

Figure 3. SNS-032 enhances ZD55-TIS-induced apoptosis and cell cycle arrest in pancreatic cancer cells. PANC-1 were infected with ZD55-TIS (8 MOI), treated with SNS-032 (160 ng/ml) or ZD55-TIS (8 MOI) plus SNS-032 (160 ng/ml). (A) After 72 h, PANC-1 cells were stained with Hoechst 33342 and observed under an inverted fluorescence microscope. White arrows indicate positive apoptotic cells. Original magnification, x200. (B) Western blotting was performed to detect cleaved caspase-9 and -3, and PARP. GAPDH was used as the loading control and the level in the untreated group was set as 1 . At $48 \mathrm{~h}$ after treatment, (C) apoptosis and (D) the cell cycle were analyzed by flow cytometry and the \% of cells in the G2 phase was calculated. Uninfected cells served as control. ZD55-TIS, ZD55-TRAIL-IETD-Smac; TRAIL, tumor necrosis factor-related apoptosis-inducing ligand; IETD, isoleucine-aspartate-threonine-glutamate; Smac, second mitochondria-derived activator of caspase; Comb, combination. PI, propidium iodide; FITC, fluorescein isothiocyanate; PARP, poly(ADP-ribose) polymerase.

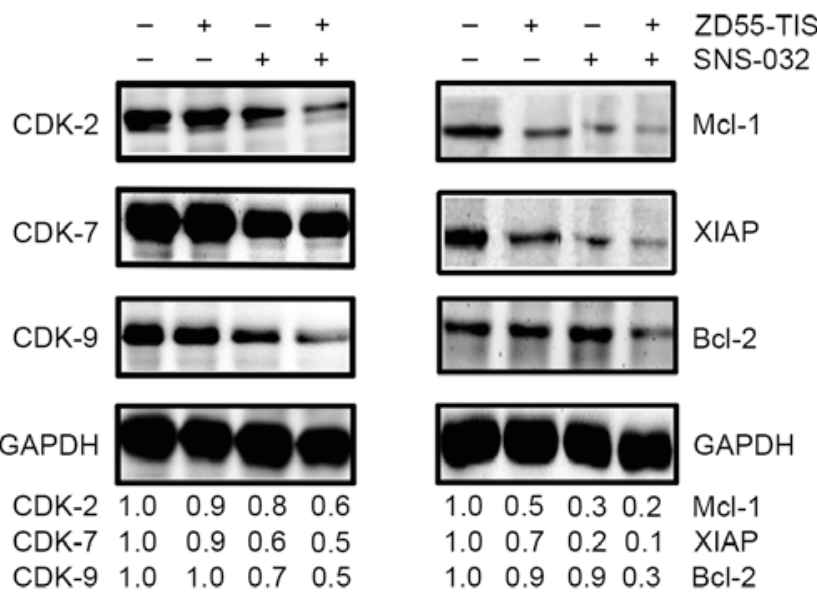

Figure 4. Effect of SNS-032 combined with ZD55-TIS on pro-apoptotic signaling elements in PANC-1 cells. PANC-1 cells were treated with ZD55-TIS (8 MOI) or/and SNS-032 (160 ng/ml). The combination of ZD55-TIS and SNS-032 downregulated the protein expression of CDK-2, -7, and -9, and XIAP, Mcl-1 and Bcl-2. ZD55-TIS, ZD55-TRAIL-IETD-Smac; TRAIL, tumor necrosis factor-related apoptosis-inducing ligand; IETD, isoleucine-aspartate-threonine-glutamate; Smac, second mitochondria-derived activator of caspase; CDK, cyclin-dependent kinase; Mcl-1, Bcl-2 family apoptosis regulator; XIAP, X-linked inhibitor of apoptosis; $\mathrm{Bcl}-2$, Bcl-2 apoptosis regulator.

-7 and -9 , and other apoptosis-associated proteins (Mcl-1, XIAP and Bcl-2) were analyzed by western blotting. The results are presented in Fig. 4. Compared with the control, the expression levels of CDK-2, -7 and -9 , and Mcl-1, XIAP and Bcl-2 were downregulated by treatment with SNS-032 $(160 \mathrm{ng} / \mathrm{ml})$ or ZD55-TRAIL-IETD-Smac (8 MOI) treatment alone in PANC-1 cells. Downregulation of CDK-2, -7, and -9 were not notable when treated with ZD55-TRAIL-IETD-Smac alone, the effects were marked when combined treatment with SNS-032 $(160 \mathrm{ng} / \mathrm{ml})$ was performed. These results indicated that SNS-032 has the synergistic effect on ZD55-TRAIL-IETD-Smac-induced apoptosis in pancreatic cells by affecting anti-apoptotic regulators, including CDK-2, CDK-9, Mcl-1 and XIAP.

SNS-032 enhances ZD55-TRAIL-IETD-Smac-mediated pancreatic tumor growth suppression in vivo. To determine the therapeutic effects of combination treatment with SNS-032 and ZD55-TRAIL-IETD-Smac in vivo, animal experiments were performed using a pancreatic tumor xenograft model established using BxPC-3 cells. Compared with the PBS group, SNS-032 group or ZD55-TRAIL-IETD-Smac group, SNS-032 plus ZD55-TRAIL-IETD-Smac significantly suppressed tumor growth $(\mathrm{P}<0.0001$ compared with ZD55-TRAIL-IETD-Smac; $\mathrm{P}<0.0001$ compared with SNS-032) in Fig. 5A. The average tumor volume in the mice receiving combination therapy was $682 \mathrm{~mm}^{3}$ at the end of the experiment (day 60). Whereas, the average volumes of mice injected with ZD55-TRAIL-IETD-Smac, SNS-032 and PBS were $1129.07 \mathrm{~mm}^{3}, 1394.18 \mathrm{~mm}^{3}$ and $2805.36 \mathrm{~mm}^{3}$, respectively (Fig. 5A). Additionally, all the tumors masses were removed for imaging and to compare the volume changes among different treatment groups (Fig. 5B). 
A

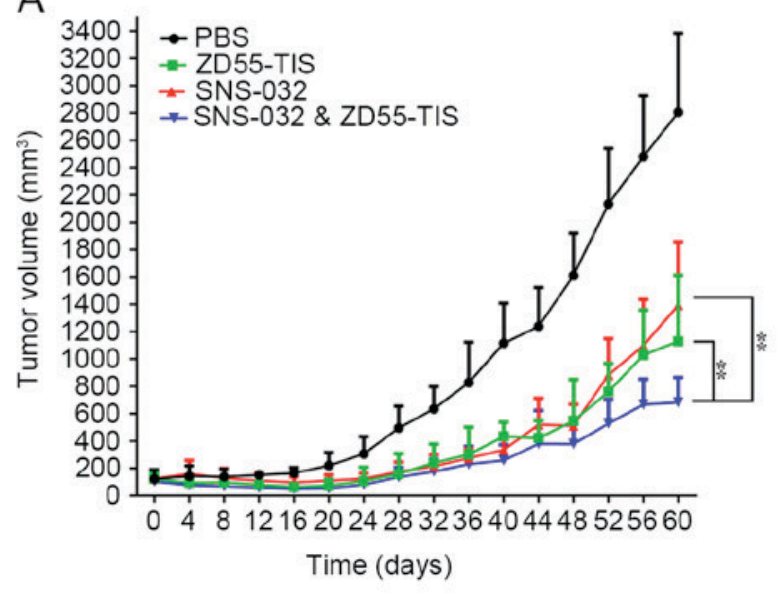

B

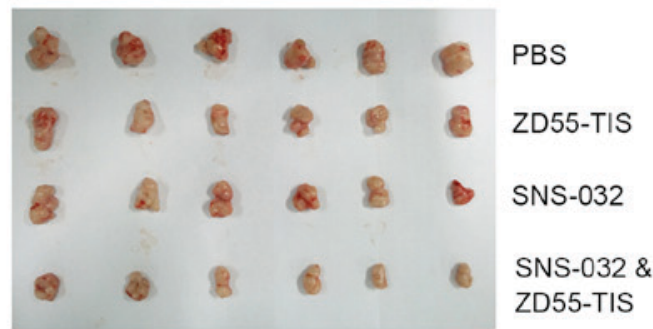

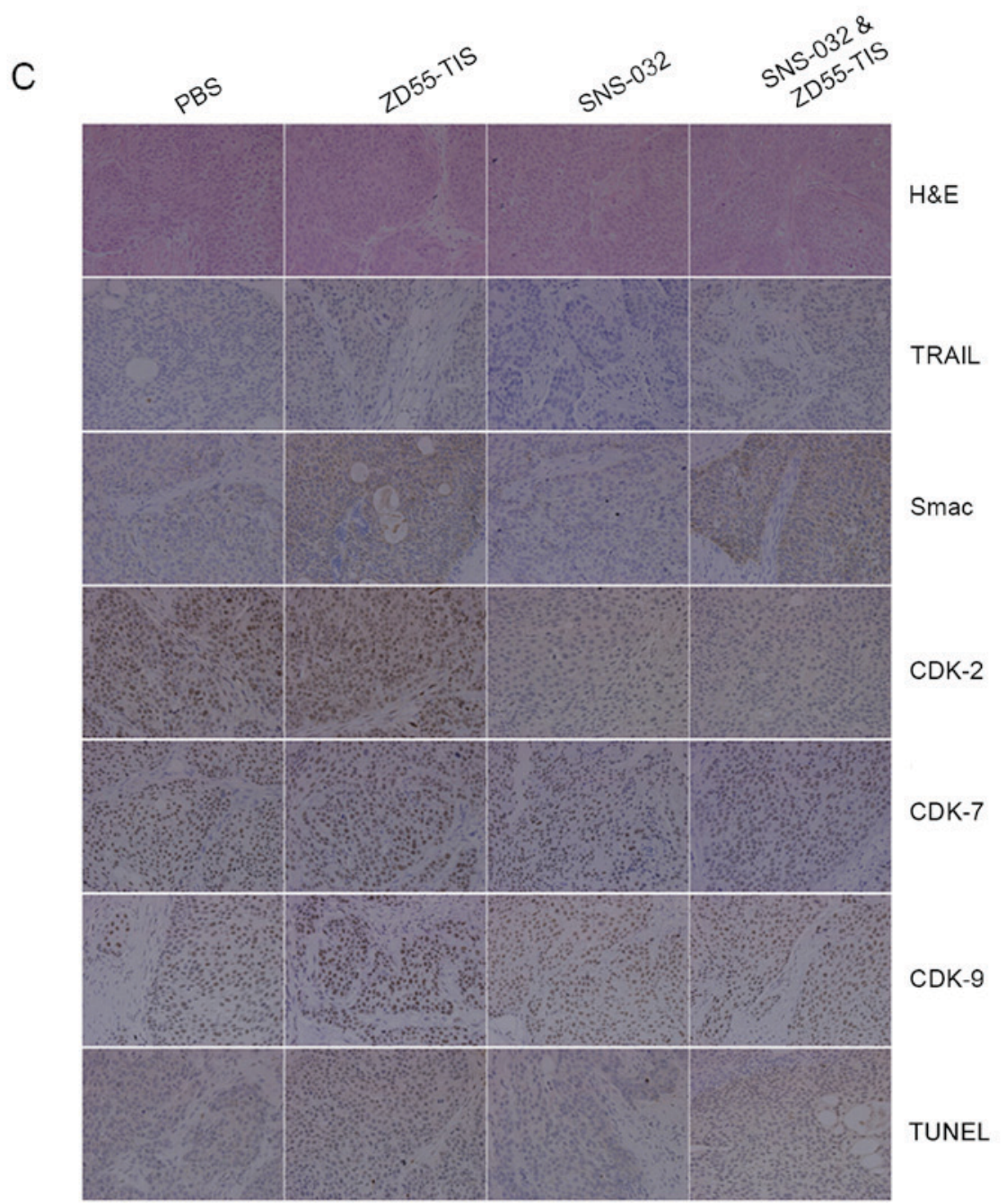

Figure 5. Synergistic effects of ZD55-TIS and SNS-032 in vivo. (A) Tumor volume was measured at different times after treatment. Data are presented as the mean \pm standard deviation $(n=7) .{ }^{* *} \mathrm{P}<0.05$, with comparisons indicated by lines. (B) The image presents inhibitory effect of each group on tumor growth at the last time point (day 60) when the mice were sacrificed. (C) Subcutaneous BxPC-3 tumors were collected 7 days after injection, and sections were analyzed by different methods. H\&E staining showed that tumor tissues treated with the combination of ZD55-TIS and SNS-032 exhibited the strongest cell death (original magnification, x400). Immunohistochemistry analysis demonstrated there was strong expression of TRAIL and Smac in xenografts treated with ZD55-TIS and the combined therapy group. However, the combined therapy group had a more obvious downregulation of CDK-2, -7 and -9 expression compared with SNS-032 alone. TUNEL assay revealed enhanced cell apoptosis in the group treated with ZD55TIS plus SNS-032. ZD55-TIS, ZD55-TRAIL-IETD-Smac; TRAIL, tumor necrosis factor-related apoptosis-inducing ligand; IETD, isoleucine-aspartate-threonine-glutamate; Smac, second mitochondria-derived activator of caspase; H\&E, hematoxylin and eosin; CDK, cyclin-dependent kinase; TUNEL, terminal deoxynucleotidyl transferase dUTP nick end labeling. 
no death/necrosis was observed in tumor tissue from the SNS-032, ZD55-TRAIL-IETD-Smac or PBS groups.

Furthermore, analysis of tumors by immunohistochemical staining using anti-TRAIL, anti-Smac, anti-CDK-2, anti-CDK-7 and anti-CDK-9 antibodies revealed that there was a strong expression of TRAIL and Smac in xenografts treated with ZD55-TRAIL-IETD-Smac and the combined therapy group. However, there was a downregulation of CDK-2, -7 and -9 in xenografts treated with SNS-032 and in the combined therapy group.

To investigate the potential mechanisms underlying tumor growth inhibition induced by ZD55-TRAIL-IETD-Smac combined with SNS-032, a TUNEL assay was used to verify whether the action of the combination therapy can lead to a pro-apoptotic effect. As demonstrated in Fig. 5C, ZD55-TRAIL-IETD-Smac plus SNS-032 caused marked cell death in the tumor.

\section{Discussion}

TRAIL, a member of the tumor necrosis factor super family, can selectively induce apoptosis in various tumor cells, but almost no toxicity in normal cells (19). The TRAIL apoptotic signaling pathway inhibitory regulation has several levels. Inhibitors of apoptosis (IAPs) can inhibit caspase activation. XIAP can directly bind and inhibits caspases-3, -7 and -9 $(20,21)$. IAP overexpression has been demonstrated to be associated with tumor resistance to apoptosis-inducing agents $(22,23)$. Hence, reducing IAP inhibition of apoptosis may be pivotal for sensitizing cancer cells to anti-cancer drugs. Additionally, by eliminating the IAP inhibition of caspases 12 and -13 , Smac and the murine homolog DIABLO promote caspase activation. In response to apoptotic stimuli, Smac is released from mitochondria into the cytosol and binds to XIAP, thereby reduced the XIAP inhibition of caspases (24). Our previous studies have demonstrated that overexpressed Smac rapidly enhances sensitivity and promotes apoptosis of hepatocellular carcinoma (HCC) cells to TRAIL and complete regression of HCC could only be achieved by the combined treatment of Smac and TRAIL (25). Furthermore, our previous study generated a novel E1B-55 K deleted oncolytic adenovirus, ZD55-TRAIL-IETD-Smac, that harbors both TRAIL and Smac genes (11). In this vector a caspase-8 cleavage site (IETD) was introduced between the genes, allowing the production of TRAIL and Smac following activation of caspase- 8 in virus-infected cells. Several in vitro and in vivo experiments have demonstrated the antitumor effects of ZD55-TRAIL-IETD-Smac in models of hepatocellular, cervical, lung, breast and colorectal cancer.

Combination targeted therapy is necessary for cancer treatment because tumors are genetically diverse and resistance seems inevitable $(26,27)$. Therefore, it is important to identify combinations of two or more therapeutic agents, which function by different mechanisms with synergistic effects without increasing adverse effects. Oncolytic virotherapy for cancer is a novel treatment strategy. However, oncolytic virotherapy has not been effective in preclinical animal tumor models and clinical trials (28). Several clinical studies have illustrated that combination of oncolytic adenoviruses with chemotherapy (29-31) or radiation therapy (32) may enhance and have synergistic antitumor activity. Oncolytic adenoviruses combined with cytotoxicitic chemotherapies may enhance the potential of oncolytic adenovirus and optimize treatment.

The aim of this study was to investigate the possibility of combining ZD55-TRAIL-IETD-Smac with SNS-032, a CDK inhibitor that may be a novel therapeutic agent for patients with pancreatic carcinoma $(18,33,34)$, and thereby enhance their antitumor activities. The MTT analysis demonstrated that combination of SNS-032 with ZD55-TRAIL-IETD-Smac was obviously superior to SNS-032 or ZD55-TRAIL-IETD-Smac alone.

In conclusion, to the best of our knowledge, the present study is the first to demonstrate that SNS-032 sensitizes human pancreatic cancer cells to ZD55-TRAIL-IETD-Smac-induced cell death in vitro and in vivo. These findings indicate that the combined treatment with SNS-032 and ZD55-TRAIL-IETD-Smac could represent a rational approach for anti-pancreatic cancer therapy.

\section{Acknowledgements}

This study was supported by the National Science Foundation of China (grant nos. 81602706, 81372463 and 81472210), the Zhejiang Provincial Natural Science Foundation of China (grant nos. LY13H080005, LY15H160051 and LY14H160041), the Funds of CONBA-ZSTU Sino-American Academician Laboratory (grant no. 14040365-J), the Funds of Science Technology Department of Zhejiang Province (grant nos. 2014C37101 and 2015C37035), the Zhejiang Province Bureau of Health (grant no. 2015ZA009) and the Open Fund of Zhejiang Provincial Top Key Discipline of Biology.

\section{References}

1. Jemal A, Siegel R, Xu J and Ward E: Cancer statistics, 2010. CA Cancer J Clin 60: 277-300, 2010.

2. Burris H and Storniolo AM: Assessing clinical benefit in the treatment of pancreas cancer: Gemcitabine compared to 5-fluorouracil. Eur J Cancer 33 (Suppl 1): S18-S22, 1997.

3. Cheng AL, Hsu CH, Lin JK, Hsu MM, Ho YF, Shen TS, Ko JY, Lin JT, Lin BR, Ming-Shiang W, et al: Phase I clinical trial of curcumin, a chemopreventive agent, in patients with high-risk or pre-malignant lesions. Anticancer Res 21: 2895-2900, 2001.

4. Lei W, Liu HB, Wang SB, Zhou XM, Zheng SD, Guo KN, Ma BY, Xia YL, Tan WS, Liu XY and Wang YG: Tumor suppressor in lung cancer-1 (TSLC1) mediated by dual-regulated oncolytic adenovirus exerts specific antitumor actions in a mouse model. Acta Pharmacol Sin 34: 531-540, 2013.

5. Hermiston TW and Kuhn I: Armed therapeutic viruses: Strategies and challenges to arming oncolytic viruses with therapeutic genes. Cancer Gene Ther 9: 1022-1035, 2002.

6. Zhang ZL, Zou WG, Luo CX, Li BH, Wang JH, Sun LY, Qian QJ and Liu XY: An armed oncolytic adenovirus system, ZD55-gene, demonstrating potent antitumoral efficacy. Cell Res 13: 481-489, 2003.

7. Dong F, Wang L, Davis JJ, Hu W, Zhang L, Guo W, Teraishi F, Ji L and Fang B: Eliminating established tumor in nu/nu nude mice by a tumor necrosis factor-alpha-related apoptosis-inducing ligand-armed oncolytic adenovirus. Clin Cancer Res 12: 5224-5230, 2006.

8. Qian W, Liu J, Tong Y, Yan S, Yang C, Yang M and Liu X: Enhanced antitumor activity by a selective conditionally replicating adenovirus combining with MDA-7/interleukin-24 for B-lymphoblastic leukemia via induction of apoptosis. Leukemia 22: 361-369, 2008.

9. Pan QW, Zhong SY, Liu BS, Liu J, Cai R, Wang YG, Liu XY and Qian C: Enhanced sensitivity of hepatocellular carcinoma cells to chemotherapy with a Smac-armed oncolytic adenovirus. Acta Pharmacol Sin 28: 1996-2004, 2007. 
10. Li J, Bonifati S, Hristov G, Marttila T, Valmary-Degano S, Stanzel S, Schnölzer M, Mougin C, Aprahamian M, Grekova SP, et al: Synergistic combination of valproic acid and oncolytic parvovirus H-1PV as a potential therapy against cervical and pancreatic carcinomas. EMBO Mol Med 5: 1537-1555, 2013.

11. Wang SB, Tan Y, Lei W, Wang YG, Zhou XM, Jia XY, Zhang KJ, Chu L, Liu XY and Qian WB: Complete eradication of xenograft hepatoma by oncolytic adenovirus ZD55 harboring TRAIL-IETD-Smac gene with broad antitumor effect. Hum Gene Ther 23: 992-1002, 2012.

12. Senderowicz AM: Inhibitors of cyclin-dependent kinase modulators for cancer therapy. Prog Drug Res 63: 183-206, 2005.

13. Dickson MA and Schwartz GK: Development of cell-cycle inhibitors for cancer therapy. Curr Oncol 16: 36-43, 2009.

14. Meng H, Jin Y, Liu H, You L, Yang C, Yang X and Qian W: SNS-032 inhibits mTORC1/mTORC2 activity in acute myeloid leukemia cells and has synergistic activity with perifosine against Akt. J Hematol Oncol 6: 18, 2013.

15. Wu Y, Chen C, Sun X, Shi X, Jin B, Ding K, Yeung SC and Pan J: Cyclin-dependent kinase 7/9 inhibitor SNS-032 abrogates FIP1-like-1 platelet-derived growth factor receptor a and bcr-abl oncogene addiction in malignant hematologic cells. Clin Cancer Res 18: 1966-1978, 2012

16. Walsby E, Lazenby M, Pepper C and Burnett AK: The cyclin-dependent kinase inhibitor SNS-032 has single agent activity in AML cells and is highly synergistic with cytarabine. Leukemia 25: 411-419, 2012.

17. Xie G, Tang H, Wu S, Chen J, Liu J and Liao C: The cyclin-dependent kinase inhibitor SNS-032 induces apoptosis in breast cancer cells via depletion of Mcl-1 and X-linked inhibitor of apoptosis protein and displays antitumor activity in vivo. Int J Oncol 45: 804-812, 2014

18. Feldmann G, Mishra A, Bisht S, Karikari C, Garrido-Laguna I, Rasheed Z, Ottenhof NA, Dadon T, Alvarez H, Fendrich V, et al: Cyclin-dependent kinase inhibitor Dinaciclib (SCH727965) inhibits pancreatic cancer growth and progression in murine xenograft models. Cancer Biol Ther 12: 598-609, 2011.

19. Walczak H, Miller RE, Ariail K, Gliniak B, Griffith TS, Kubin M, Chin W, Jones J, Woodward A, Le T, et al: Tumoricidal activity of tumor necrosis factor-related apoptosis-inducing ligand in vivo. Nat Med 5: 157-163, 1999.

20. Chai J, Shiozaki E, Srinivasula SM, Wu Q, Datta P, Alnemri ES and Shi Y: Structural basis of caspase-7 inhibition by XIAP. Cell 104: 769-780, 2001.

21. Suzuki Y, Nakabayashi Y, Nakata K, Reed JC and Takahashi R: $\mathrm{X}$-linked inhibitor of apoptosis protein (XIAP) inhibits caspase-3 and -7 in distinct modes. J Biol Chem 276: 27058-27063, 2001.

22. Tamm I, Kornblau SM, Segall H, Krajewski S, Welsh K, Kitada S, Scudiero DA, Tudor G, Qui YH, Monks A, et al: Expression and prognostic significance of IAP-family genes in human cancers and myeloid leukemias. Clin Cancer Res 6: 1796-1803, 2000.
23. Ambrosini G, Adida C and Altieri DC: A novel anti-apoptosis gene, survivin, expressed in cancer and lymphoma. Nat Med 3: 917-921, 1997.

24. Srinivasula SM, Hegde R, Saleh A, Datta P, Shiozaki E, Chai J, Lee RA, Robbins PD, Fernandes-Alnemri T, Shi Y and Alnemri ES: A conserved XIAP-interaction motif in caspase-9 and Smac/DIABLO regulates caspase activity and apoptosis. Nature 410: 112-116, 2001.

25. Pei Z, Chu L, Zou W, Zhang Z, Qiu S, Qi R, Gu J, Qian C and Liu X: An oncolytic adenoviral vector of Smac increases antitumor activity of TRAIL against HCC in human cells and in mice. Hepatology 39: 1371-1381, 2004

26. Levinson AD: Cancer therapy reform. Science 328: 137, 2010.

27. Ehrhardt H, Häcker S, Wittmann S, Maurer M, Borkhardt A, Toloczko A, Debatin KM, Fulda S and Jeremias I: Cytotoxic drug-induced, p53-mediated upregulation of caspase-8 in tumor cells. Oncogene 27: 783-793, 2008.

28. Chu RL, Post DE, Khuri FR and Van Meir EG: Use of replicating oncolytic adenoviruses in combination therapy for cancer. Clin Cancer Res 10: 5299-5312, 2004

29. Kruyt FA and Curiel DT: Toward a new generation of conditionally replicating adenoviruses: Pairing tumor selectivity with maximal oncolysis. Hum Gene Ther 13: 485-495, 2002.

30. Post DE, Khuri FR, Simons JW and Van Meir EG: Replicative oncolytic adenoviruses in multimodal cancer regimens. Hum Gene Ther 214: 933-946, 2003.

31. Libertini S, Iacuzzo I, Ferraro A, Vitale M, Bifulco M, Fusco A and Portella G: Lovastatin enhances the replication of the oncolytic adenovirus d11520 and its antineoplastic activity against anaplastic thyroid carcinoma cells. Endocrinology 148: 5186-5194, 2007.

32. Pan JJ, Zhang SW, Chen CB, Xiao SW, Sun Y, Liu CQ, Su X, Li DM, Xu G, Xu B and Lu YY: Effect of recombinant adenovirus-p53 combined with radiotherapy on long-term prognosis of advanced nasopharyngeal carcinoma. J Clin Oncol 27: 799-804, 2009.

33. Subramaniam D, Periyasamy G, Ponnurangam S, Chakrabarti D, Sugumar A, Padigaru M, Weir SJ, Balakrishnan A, Sharma S and Anant S: CDK-4 inhibitor P276 sensitizes pancreatic cancer cells to gemcitabine-induced apoptosis. Mol Cancer Ther 11: 1598-1608, 2012.

34. Hu C, Dadon T, Chenna V, Yabuuchi S, Bannerji R, Booher R, Strack P, Azad N, Nelkin BD and Maitra A: Combined inhibition of cyclin-dependent kinases (Dinaciclib) and AKT (MK-2206) blocks pancreatic tumor grow th and metastases in patient-derived xenograft models. Mol Cancer Ther 14: 1532-1539, 2015. 